\title{
Diversity and distribution of heterotrophic flagellates in seawater of the Powell Basin, Antarctic Peninsula
}

\author{
Zhiyi Chen, ${ }^{1,2}$ Jianfeng He, ${ }^{1,2}$ Shunan Cao, ${ }^{2}$ Zhibo Lu, ${ }^{1}$ Musheng Lan, ${ }^{2}$ Hongyuan Zheng, ${ }^{1}$ \\ Guangfu Luo ${ }^{2}$ \& Fang Zhang ${ }^{2}$ \\ ${ }^{1}$ College of Environmental Science and Engineering, Tongji University, Shanghai, China; \\ ${ }^{2}$ Key Laboratory for Polar Science of Natural Resources Ministry, Polar Research Institute of China, Shanghai, China
}

\begin{abstract}
Heterotrophic flagellates are essential components of the marine microbial food web. However, how the changes in flagellate populations reflect environmental changes in marine ecosystems is still unclear, especially in polar regions. In this study, we used pyrosequencing to examine the community structure of heterotrophic flagellates (HFs) in the Powell Basin's surface waters of the northern Antarctic Peninsula. OTUs (operational taxonomic units) of different taxa and the correlations between community structure and environmental factors were analysed. Eight taxa of HFs were selected for the principal analysis: Telonemia, Picozoa, Rhizaria, Amoebozoa, Apusomonas, Centrohelida, Choanomonada and marine stramenopiles (MASTs). The HFs were defined as heterotrophic picoflagellates (HPFs; $<3 \mu \mathrm{m}$ ) and heterotrophic nanoflagellates (HNFs; $>3 \mu \mathrm{m},<20 \mu \mathrm{m}$ ), which had similar dominant phyla (MASTs and Telonemia). However, their taxonomic composition differed. Environmental factors exerted similar effects on the community structure of both HPFs and HNPs. Compared with the correlation between HPF and environmental factors, the correlation between HNF and environmental factors was stronger. Salinity, bacterial biomass and the biological interactions amongst dominant taxa were the main variables to influence the diversity and community structure of HFs.
\end{abstract}

To access the supplementary material, please visit the article landing page

\section{Keywords}

Heterotrophic picoflagellates; heterotrophic nanoflagellates; biodiversity; community structure

\section{Correspondence}

He Jianfeng, Key Laboratory for Polar Science, State Ocean Administration, Polar Research Institute of China, 451 Jingiao Road, Pudong, Shanghai 200136, China. E-mail: hejianfeng@pric.org.cn

\author{
Abbreviations \\ ACE: abundance-based coverage estimator \\ chl a: chlorophyll $a$ \\ CTAB: cetyltrimethylammonium bromide \\ CTD: conductivity-temperature-depth \\ instrument \\ DOC: dissolved organic carbon \\ HF: heterotrophic flagellate \\ HPF: heterotrophic picoflagellate \\ HNF: heterotrophic nanoflagellate \\ MAST: marine stramenopiles \\ MWM: mixed water mass \\ NCBI: National Center for Biotechnology \\ Information \\ OTU: operational taxonomic unit \\ PCR: polymerase chain reaction \\ RDA: redundancy analysis \\ WDW: Weddell Deep Water
}

\section{Introduction}

HFs play a crucial role in the microbial food web, being critical consumers of marine plankton, including heterotrophic bacteria, cyanobacteria and eukaryotic algae (Arndt et al. 2000; Sherr \& Sherr 2002; Domaizon et al. 2003). Moreover, their feeding rates directly affect material circulation and nutrient regeneration in the ecosystem (Bonkowski 2004; Massana et al. 2004), significantly influencing plankton's community structure. Identification and quantification of ecologically significant groups can improve our understanding of marine ecosystems. HFs are widely distributed across the global oceans, including the polar regions, with different characteristic taxonomic compositions in different geographic regions (Sohrin et al. 2010). In recent years, with the development of molecular biology techniques, it has been demonstrated that HFs exist in almost all lineages of eukaryotes in the areas studied, and several studies have shown that HF communities are rarely dominated by a single or several species (Lovejoy et al. 2007; Massana 2011). Because most HFs lack easily recognizable morphological features, studies of the primary distributions of HFs are limited (Monier et al. 2013). 
The global warming and sea-ice melting are altering the polar habitat and marine protozoan communities, including HFs. Though all levels of the marine microbial food web may respond to climate change (Fortier et al. 2006; Falk-Petersen et al. 2007; Laidre et al. 2008), the nano- and pico-levels of plankton, where HFs' biomass is mainly concentrated (Rodriguez-Martinez et al. 2013), are especially sensitive to environmental changes (Li et al. 2009; Zhang et al. 2015). In recent years, the single-celled organisms are gradually tending to form smaller cell structure (Li et al. 2009), which suggests that the community structure and biodiversity of HFs may be greatly altered under the circumstances of climate change.

The factors affecting the distribution of microorganisms (including HFs) are still controversial because our understanding of the fundamental biogeography and environmental selection forces acting on different $\mathrm{HF}$ taxa is limited (Hanson et al. 2012; Monier et al. 2013). For the global marine plankton, there are still gaps in our knowledge of the dominant populations of HFs in various regions, especially in the polar regions (Arndt et al. 2000). Fewer studies have characterized the functional diversity of different HFs. Some researchers have suggested a non-random dispersion mechanism of the HF's community structure on the basis of some studies in the environments of anoxic basins and Arctic water masses (Hamilton et al. 2008; Orsi et al. 2011 ; Filker et al. 2013). Other studies have hypothesized that dispersal barriers to protist distributions are not necessary (Fenchel \& Finlay 2004; Cermeno \& Falkowski 2009), but that environmental gradients affect some flagellate distribution (Thaler \& Lovejoy 2015). Other studies have suggested that community structure differences can be sensitive indicators of external environmental factors (Jones \& Lennon 2010). Therefore, to understand and predict changes in marine organism distributions, it is necessary to clarify how environmental variables determine these distributions.

In this study, HFs were divided into two size groups: HPFs $(x<3 \mu \mathrm{m})$ and HNFs $(3 \mu \mathrm{m}<x<20 \mu \mathrm{m})$. These were analysed to determine the distributions of individual taxa and increase the data available on microbial ecosystems in coastal regions of the Antarctic. This study aimed to understand the abundance and diversity of HPFs and HNFs in the Powell Basin and nearby areas around the northern Antarctic Peninsula and investigate the influence of environmental factors, such as temperature, salinity, chl a concentration and nutrients, on HF community structure and abundances.

\section{Materials and methods}

\section{Sample collection}

Samples were collected between 30 December 2011 and 29 January 2012, during the 28th Chinese National Antarctic Research Expedition. Four sampling sections and 13 sampling stations were established around the northern Antarctic Peninsula, including in the Powell Basin and its surrounding area $\left(60.10^{\circ} \mathrm{S}-63.15^{\circ} \mathrm{S}\right.$, $\left.44.68^{\circ} \mathrm{W}-54.68^{\circ} \mathrm{W}\right)$, from Elephant Island to the Southern Orkney tableland area, including the northern area of Bransfield Strait (Fig. 1). The samples were taken from the layer of maximum oxygen, a depth of $25 \mathrm{~m}$.

The water samples were collected using a SBE91 l plus CTD instrument (Sea-Bird Electronics) equipped with



Fig. 1 Location of sampling stations in the Powell Basin, northern Antarctic Peninsula. 
24 Niskin bottles. Physical parameters (temperature and salinity) were measured at the same time as sampling. About 2 L of seawater was prefiltered through a $20-\mu \mathrm{m}$ mesh sieve to remove most mesozooplankton and large particles. Each sample was then filtered through a 3- $\mu \mathrm{m}$ pore size polycarbonate membrane (all membranes were from Whatman), to retain the nano-sized HFs. The filtrate was finally filtered through a polycarbonate membrane (diameter $47 \mathrm{~mm}$ and pore size $0.2 \mu \mathrm{m}$ ) with vacuum pumping to retain the pico-sized HFs. The membrane samples were immediately frozen at $-80^{\circ} \mathrm{C}$ and shipped to the laboratory for microbial diversity analysis. Each water sample was filtered through a 0.45$\mu \mathrm{m}$ cellulose acetate membrane filter (Whatman) for nutrient analysis. Nitrite $\left(\mathrm{NO}_{2}\right)$, nitrate $\left(\mathrm{NO}_{3}\right)$, phosphate $\left(\mathrm{PO}_{4}\right)$ and silicate $\left(\mathrm{SiO}_{3}\right)$ were measured with a San++ nutrient autoanalyser (Skalar), using methods explained by Müller (2007) and He et al. (2012). Ammonia $\left(\mathrm{NH}_{4}\right)$ was analysed using a spectrophotometer. To determine the chl a concentration, about $2 \mathrm{~L}$ of seawater in each sample was filtered through a $47-\mathrm{mm}$ diameter Whatman GF/F filter. The filter was fully leached with $90 \%$ acetone and stored at $-20^{\circ} \mathrm{C}$ for 24 hr. Analysis was conducted onboard in the research vessel using a 10 AU field fluorometer (Turner Designs), by the methods of He et al. (2012). The amount of eukaryotic plankton and bacteria were detected by a BD FACSCalibur ${ }^{\mathrm{TM}}$ flow cytometer.

\section{DNA sequencing and 185 rRA sequence analyses}

To analyse the biodiversity and community composition, the DNA extraction, PCR amplification of rRNA genes and the pyrosequencing and bioinformatics analyses were completed in the Key Laboratory for Polar Science of Natural Resources Ministry in Shanghai. The DNA extraction was conducted by the CTAB method. The CTAB solution was treated using lysozyme (final concentration, $5 \mathrm{mg} \mathrm{mL}^{-1}$ ) and proteinase $\mathrm{K}$ (final concentration, $\left.10 \mathrm{mg} \mathrm{mL}^{-1}\right)$. Samples were put in the CTAB solution with a final concentration of $2 \%(1.4 \mathrm{M} \mathrm{NaCl}, 100 \mathrm{mM}$ Tris$\mathrm{HCl}, 4 \%$ PVP, $70 \mathrm{mM} \beta$-mercaptoethanol, $\mathrm{pH}$ 8.0) to extract the DNA. RNase was added (final concentration, $20 \mu \mathrm{g} \mathrm{ml}$ ) to remove the RNA contamination. The final concentration and purity were checked by $0.7 \%$ agarose gels. Moreover, the PCR amplification was completed by the $\mathrm{V} 4$ region of the $18 \mathrm{~S}$ rRNA. The amplification was under the condition of the universal primer pair 3NDf (5'-GGCAAGTCTGGTGCCAG-3') and the reverse primers V4_euk_R2 (5'-ACGGTATCTRATCRTCTTCG-3') (Brate et al. 2010). The PCRs were carried out in $20 \mu \mathrm{L}$ reaction volumes with a 20-ng DNA template, $250 \mu \mathrm{M}$ dNTPs,
$0.25 \mu \mathrm{M}$ of each primer, IX PCR buffer and 2.5 U Pfu Polymerase (Fermentas). The PCR condition involved initial denaturation at $95^{\circ} \mathrm{C}$ for $2 \mathrm{~min}$, followed by 25 cycles of denaturation at $94^{\circ} \mathrm{C}$ for $30 \mathrm{~s}$, annealing at $55^{\circ} \mathrm{C}$ for $30 \mathrm{~s}$ and extension at $72^{\circ} \mathrm{C}$ for $30 \mathrm{~s}$, with a final extension of $72^{\circ} \mathrm{C}$ for $10 \mathrm{~min}$. PCR products $(3 \mu \mathrm{L})$ were checked on a $2 \%$ agarose gel, purified using a DNA gel extraction kit (Axygen, China). All the final products from the samples were mixed in the equal ratios for the Pyrosequencing with Genome Sequencer FLX Titanium (454/Roche Life Sciences). More detail process, conditions and laboratory analysis were obtained in the previous study (Zhang et al. 2019).

A bioinformatics analysis was conducted. Mothur software, version 1.32.0 (Schloss et al. 2009), was used to extract the nonrepetitive sequences and identify and remove duplicate sequences. The sequences with high qualities ( $\geq 200$ bp length, quality score $\geq 25$, matched to barcode and primer and containing no ambiguous characters) were aligned with the reference sequences in the Silva RNA database (Silva seed v115; Pruesse et al. 2007) and were clustered to OTUs at $97 \%$ similarity with a cut-off of 80 compared with the reference sequences. The community diversity and similarity amongst all water samples were also analysed with OTUs of $97 \%$ similarity in Perl and Mothur (Schloss et al. 2009). The attributions of each sequence at different levels (from phylum to genus) were added according to the NCBI database. The sequence data were submitted to the NCBI Sequence Read Archives under BioProject number PRJNA642996.

\section{Diversity and community structure analyses}

A sampling map was generated using the Ocean Data View (Schlitzer et al. 2018) software and modified with Adobe Photoshop CC 2015. The R software (version 3.4.4; McKenna et al. 2016) was used to determine the $\alpha$-diversity indices (ACE, Chao, Shannon's diversity, Simpson's index and Good's coverage) based on the normalized sequence data. Spearman's correlation analyses were performed at the OTU level with the complot package in $\mathrm{R}$ (version 3.4.4) to investigate the significance of the correlations between various environmental factors (temperature, salinity, nutrients, chl $a$, eukaryotic plankton and bacteria) and the HF communities. An RDA was performed using the Canoco 5 programme to assess the correlations between the variations in the communities at the 13 Antarctic locations (based on the relative abundances of all OTUs) and environmental variables (temperature, salinity, nutrients, chl $a$, eukaryotic plankton and bacteria). 


\section{Results}

\section{Basic environmental parameters and $\alpha$-diversity indices}

The seawater properties at the 13 sampling stations were measured to a depth of $25 \mathrm{~m}$ (Supplementary Table S1). During the sampling period, water temperature ranged from -1.30 to $1.16^{\circ} \mathrm{C}$, and the salinity was 33.58-34.50 psu. The chl $a$ levels varied from $0.08 \mu \mathrm{g} / \mathrm{L}$ at station D3-8 to $2.11 \mu \mathrm{g} / \mathrm{L}$ at station D5-3. The density of phototrophic picoeukaryotes varied from $1.78 \times$ $10^{6}$ cells/L at station D3-3 to $7.99 \times 10^{6}$ cells/L at station D3-5. The density of heterotrophic bacteria was $1.64 \times 10^{8}$ to $6.09 \times 10^{8}$ cells/L. The highest bacterial biomass occurred at station D4-7, with another two peaks at D3-5 and D5-3. Seawater $\left[\mathrm{PO}_{4}\right]$ was 1.55-2.34 $\mu \mathrm{M},\left[\mathrm{NO}_{2}\right]$ was $0.10-0.34 \mu \mathrm{M},\left[\mathrm{NO}_{3}\right]$ was $25.04-47.53$ $\mu \mathrm{M},\left[\mathrm{NH}_{4}\right]$ was $25.04-47.53 \mu \mathrm{M}$ and $\left[\mathrm{SiO}_{3}\right]$ was $66.25-$ $87.10 \mu \mathrm{M}$.

In this study, 159-664 OTUs were detected in the HPF group and 97-450 in the HNF group (Table 1). Good's coverage was $84-94 \%$ in the HPF group and $82-93 \%$ in the HNF group, indicating that the vast majority of OTUs were sequenced. Specimens from samples D3-3 in the HPF group and D5-8 in the HNF group showed the highest ACE (4062 and 4108, respectively) and Chao indices (6387 and 7058, respectively), indicating that the highest community richness occurred at these sites. The highest Shannon index in the HPF group occurred in samples D4-7 (6.02), followed by samples D5-1 (5.56) and D2-5 (5.16). In the HNF group, the highest value occurred in samples D3-3 (5.70), followed by samples D4-7 (5.46) and D5-1 (5.20). The highest Simpson's index of the HPF group was detected in sample D3-1 (0.60), followed by samples D2-3 (0.578) and D2-5 (0.577); in the HNF group, the highest value occurred in sample D2-5 (0.72), followed by samples D2-3 (0.65) and D3-1 (0.60). Therefore, these samples had the most significant community diversity.

\section{HF community composition}

The libraries' coverage at a cluster distance of 0.03 was high for all 13 samples, and the rarefaction curves reached saturation. The sequence data showed the abundance of each phyla or genera, and the OTU data showed the diversity of HFs community. HPF and HNF richness differed significantly across all the samples. HPF reads' mean richness was 2625 (range 645-8474 reads), with a peak at site D5-8. The mean richness of HNF reads was 1234 (range 215-3781 reads), with a peak at D3-5 (Table 1). The HNF communities exhibited similar abundances and levels of diversity to the HPF communities. Eight major HPF taxa were identified in the communities in the Powell Basin, and seven major HNF taxa were detected in the samples. The reads of each taxa identified were present at relatively high abundance.

In this study, MASTs, Telonemia and Rhizaria were frequently detected at high biodiversity. The dominant taxon in all samples was MASTs, which accounted, on average, for $63.86 \%$ of the total OTUs in the HPF group and $52.93 \%$ of the total OTUs in the HNF group (Fig. 2f). Telonemia was the second most represented taxon, accounting for $15.96 \%$ of the total OTUs in the HPF group and for $26.72 \%$ of the total OTUs in the HNF

Table 1 Comparison of the richness and diversity indices for estimated OTUs (clustered at 97\% identity) based on 18S rRNA gene libraries, determined with a pyrosequencing analysis of Antarctic waters.

\begin{tabular}{|c|c|c|c|c|c|c|c|c|c|c|c|c|c|c|}
\hline \multirow{2}{*}{$\begin{array}{l}\text { Sample } \\
\text { ID }\end{array}$} & \multicolumn{7}{|c|}{ HPF } & \multicolumn{7}{|c|}{ HNF } \\
\hline & Coverage & OTU & Reads & Chao & ACE & Shannon & Simpson & Coverage & OTU & Reads & Chao & ACE & Shannon & Simpson \\
\hline D2-3 & 0.8952 & 323 & 1817 & 3014 & 5321 & 4.63 & 0.5779 & 0.9004 & 153 & 619 & 3446 & 6055 & 4.27 & 0.6543 \\
\hline D2-5 & 0.8903 & 297 & 1580 & 3164 & 5176 & 5.16 & 0.5767 & 0.8968 & 121 & 377 & 3336 & 5728 & 4.29 & 0.7175 \\
\hline D2-8 & 0.9179 & 150 & 645 & 2551 & 3968 & 4.34 & 0.5149 & 0.8834 & 159 & 724 & 3656 & 6730 & 4.64 & 0.4975 \\
\hline D3-1 & 0.8764 & 400 & 2016 & 3019 & 5117 & 5.04 & 0.6035 & 0.9102 & 195 & 709 & 2532 & 4067 & 3.91 & 0.6002 \\
\hline D3-3 & 0.8820 & 307 & 1285 & 4062 & 6387 & 5.09 & 0.5296 & 0.8396 & 109 & 256 & 4094 & 6489 & 5.70 & 0.7206 \\
\hline D3-5 & 0.9143 & 436 & 2955 & 2917 & 4607 & 4.35 & 0.2612 & 0.9023 & 442 & 3781 & 3276 & 4744 & 4.56 & 0.4725 \\
\hline D3-8 & 0.8986 & 316 & 2253 & 3380 & 5590 & 4.96 & 0.4878 & 0.8828 & 229 & 1591 & 3304 & 5625 & 5.17 & 0.3138 \\
\hline D4-7 & 0.8439 & 425 & 1817 & 4042 & 6012 & 6.02 & 0.3630 & 0.8200 & 450 & 215 & 3302 & 5251 & 5.46 & 0.4200 \\
\hline D4-11 & 0.9126 & 459 & 2789 & 3150 & 5021 & 3.96 & 0.1065 & 0.8758 & 97 & 3248 & 3874 & 6429 & 4.94 & 0.2322 \\
\hline D5-1 & 0.8739 & 347 & 1312 & 3797 & 5977 & 5.56 & 0.3976 & 0.8693 & 170 & 561 & 3543 & 6070 & 5.20 & 0.4998 \\
\hline D5-3 & 0.8961 & 371 & 2278 & 3909 & 6043 & 5.07 & 0.4221 & 0.8902 & 145 & 891 & 3278 & 5480 & 5.00 & 0.3127 \\
\hline D5-6 & 0.9036 & 664 & 5301 & 3497 & 5404 & 4.97 & 0.5135 & 0.9281 & 305 & 1398 & 2523 & 4431 & 3.48 & 0.4641 \\
\hline D5-8 & 0.9399 & 494 & 8474 & 2666 & 4380 & 4.07 & 0.5596 & 0.8835 & 379 & 1677 & 4108 & 7058 & 4.89 & 0.4925 \\
\hline
\end{tabular}


group, on average. MASTs (including MAST-1A, MAST-1B, MAST-1C, MAST-2, MAST-3, MAST-7, MAST8, MAST-9 and MAST-12), Amoebozoa, Apusomonas, Centrohelida, choanoflagellates, Rhizaria and Telonemia were observed in both the HPF and HNF groups, whereas Picozoa $(4.12 \%$ of the total OTUs and $16.03 \%$ of sequences, on average) was only found in the HPF group, accounting for the third largest proportion. Rhizaria was the third most represented group in the HNF group, whereas in the HPF group, there were fewer sequences of Rhizaria than Picozoa. Rhizaria was also the third most represented HF taxon at the OUT level, accounting for slightly more HFs than Picozoa. In addition to the most dominant taxa, Amoebozoa, Apusomonas and Centrohelida were detected at relatively low abundances. Some of these were only detected in a subset of samples in this region (Fig. 2).

The community structure in most of the stations was similar, as showed by the proportions of OTUs at each station (Fig. 2a, b). The total number of OTUs in the HNF group was lower than that in the HPF group, and HNF's diversity was higher at D3-5 and D4-11 than at the other stations in the same section. In the HPF group, station D2-8 exhibited relatively lower reads and diversity than the other stations. In contrast, the group's diversity and sequences were higher at D5-6 and D5-8 than at the other stations. MASTs accounted for the most substantial proportion of OTUs, and Telonemia constituted the second largest proportion of OTUs at all the stations, except D5-3 and D5-8 (Fig. 2a). At D5-8, Picozoa accounted for the highest proportion of OTUs, followed by Amoebozoa, with a very similar proportion. However, Picozoa was rarely found at the other stations, with the sequence presence being lower than $1.62 \%$ (Fig. 3). The most significant difference between the HNF and HPF groups was that Picozoa was not detected amongst the HNFs. MASTs accounted for the highest proportion of OTUs at all stations, except D5-3 (Fig. 2a, b), where Rhizaria constituted the highest proportion of OTUs, followed by MASTs. At D2-5, choanoflagellates accounted for the second-largest proportion of OTUs, and Rhizaria provided the second largest proportion of OTUs at D3-3. In contrast, Telonemia formed the second largest proportion of OTUs at the other stations. The community structure at D5-3 was significantly different from those at the other stations. In the HPF group, Amoebozoa and Centrohelida were not found at every station, and the distribution of Apusomonas was also patchy in the HNF group. The other four taxa were detected in all samples.

In this research, MAST- 1 did not account for the most significant proportion of OTUs in the HPF group, and MAST-3 and MAST-7 accounted for the most generous proportions at most stations (Fig. 2c, d). However, in the HNF group, MAST-1 made up the largest proportion at most stations. The proportion of MAST-3 was higher than in the HPF group at some stations, and the proportion of MAST-7 was significantly lower than for the HPF group. The number of nano-MASTs was significantly lower than the number of pico-MASTs, with peaks at D3-5, D3-8 and D4-11, as for the pico-MAST group. D5-8 was a unique station insofar as nano-MASTs outnumbered picoMASTs. MAST-9 was not detected in the HNF group. In both the HNF and HPF groups, within the MAST-1 clade, MAST-1C accounted for the highest proportions of OTUs and reads at each station (Fig. 3). MAST-1 A accounted for a proportion similar to that of MAST-1B in the HPF group, but in the HNF group, MAST-1A accounted for a higher proportion than in the HPF group; MAST-1B was rarely detected.

\section{Correlations between environmental factors and HNF or HPF communities}

RDA ordination was carried out to analyse the relationships between the HF communities and the environmental variables at these Antarctic locations. In the RDA ordination of HPF (Fig. 4), the eigenvalues for axes I and II were 0.444 and 0.643 , respectively, and the taxa-environment correlations for the first two axes were 0.99 and 0.99 , respectively. Salinity and chl $a$ accounted for the most significant amount of variability in the HPF community, followed by temperature, but $\left[\mathrm{NH}_{4}\right]$ was also a highly significant explanatory variable along the second axis. The RDA results for HNF demonstrated that the HNF community compositions differed somewhat from those of the HPF group. The eigenvalues for axes I and II were 0.362 and 0.590 , respectively, and the taxa-environment correlations for the first two axes were 0.99 and 0.97 , respectively. Salinity accounted for the most significant variability in the HNF community, followed by $\left[\mathrm{PO}_{4}\right]$ and $\left[\mathrm{NH}_{4}\right]$, but bacteria density was also a highly significant explanatory variable along the second axis.

In the HNF group, most of the dominant taxa exhibited significant correlation with environmental factors, except Apusomonas, Centrohelida, MAST-1B and MAST-12. Different environmental factors had different effects, as indicated by the correlation coefficients for HNF (Fig. 5). For example, salinity had a significant effect on most clades of MASTs (including MAST-1A, MAST-1C, MAST-2, MAST-3 and MAST-8), choanoflagellates and Rhizaria; ammonia harmed Amoebozoa and Rhizaria but a positive effect on MAST-7 and MAST-8. MAST-2 and MAST-3 showed opposite correlations with temperature. In summary, there were only three taxa in HPF groups that displayed a significant correlation with only one of the measured factors, and most taxa showed significant correlations with more than two environmental factors. In the HPF group, only a small proportion of the dominant taxa showed a significant 




(a)

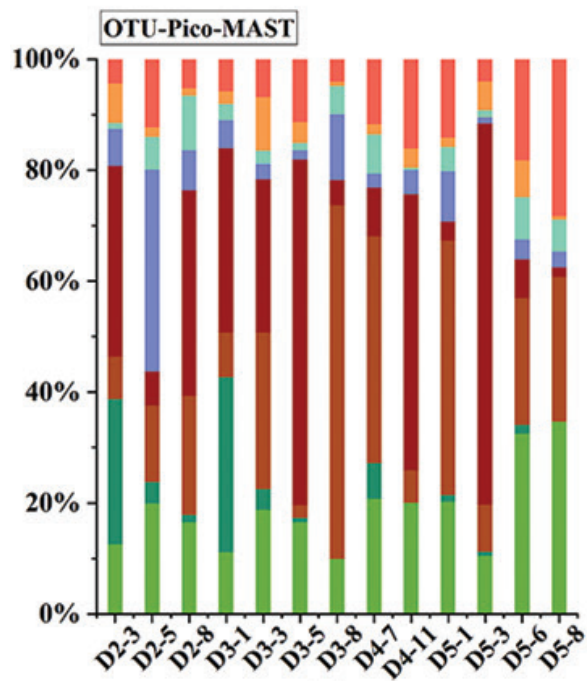

(c)

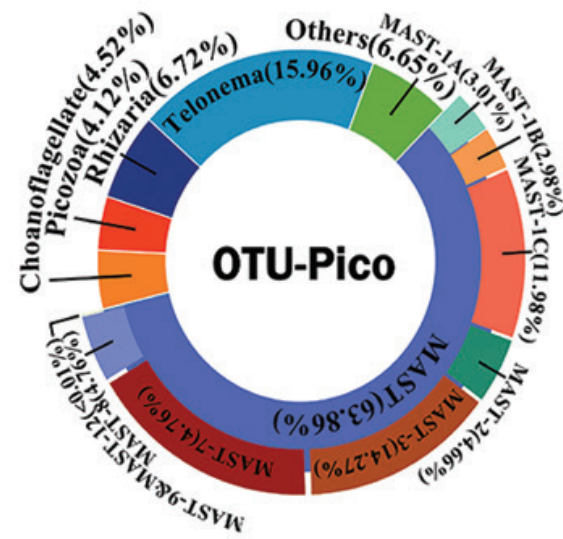

(e)

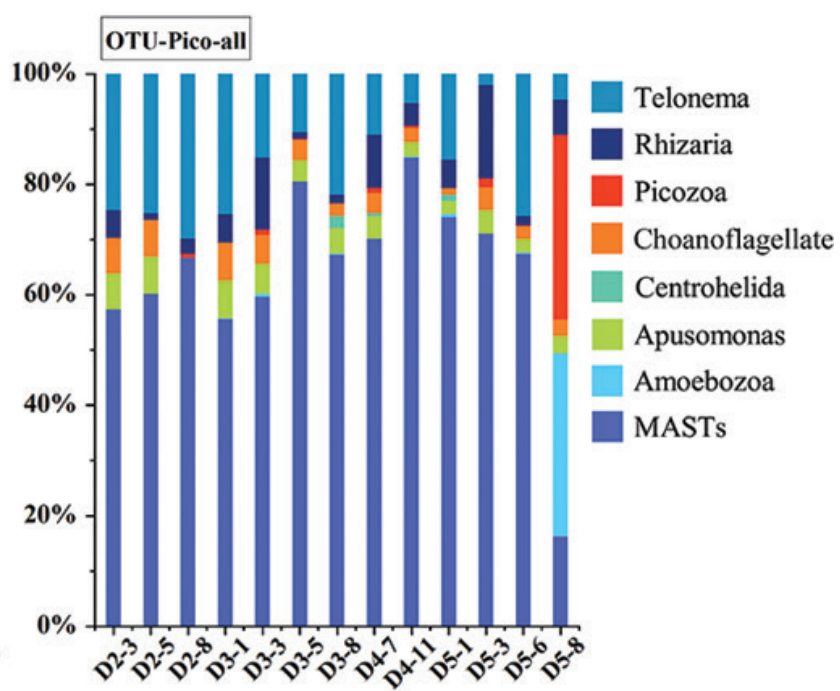

(b)

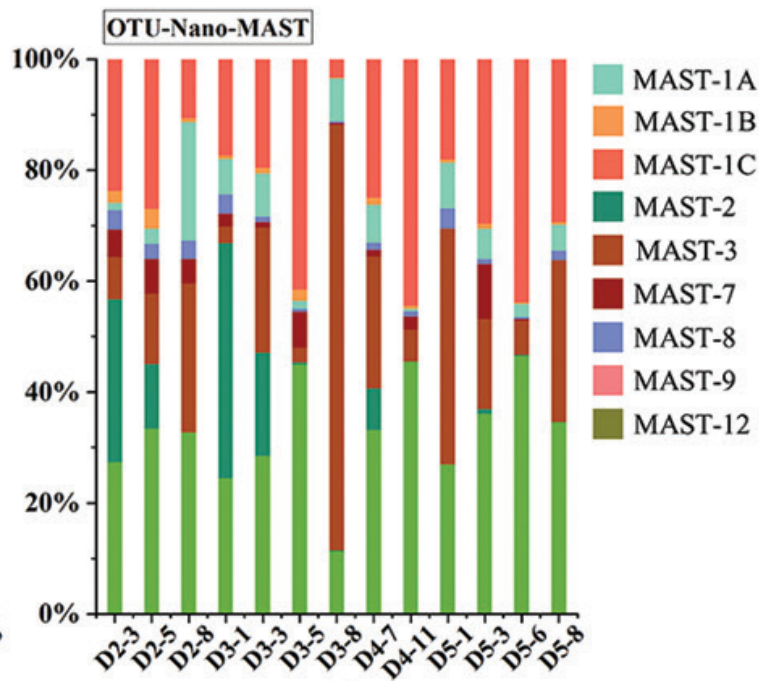

(d)

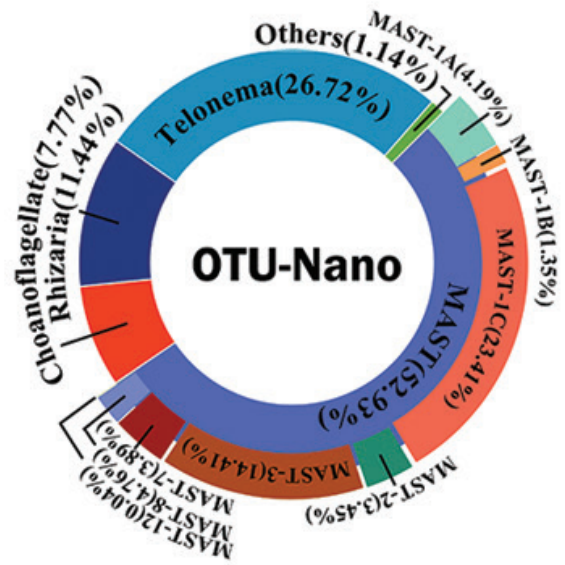

(f)

Fig. 2 Average relative percentages of OTUs for each heterotrophic flagellate group within different communities. "Others" includes Amoebozoa, Apusomonas and Centrohelida. (a) The average percentage of all taxa's relative OTU in HPF group; (b) the average percentage of all taxa's relative OTU in HNF group; (c) the average percentage of MAST's relative OTU in HPF group; (d) the average percentage of MAST's relative OTU in HNP group; (e) average relative percentages of OTU at pico-level; ( $f$ ) average relative percentages of OTU at the nano-level. 


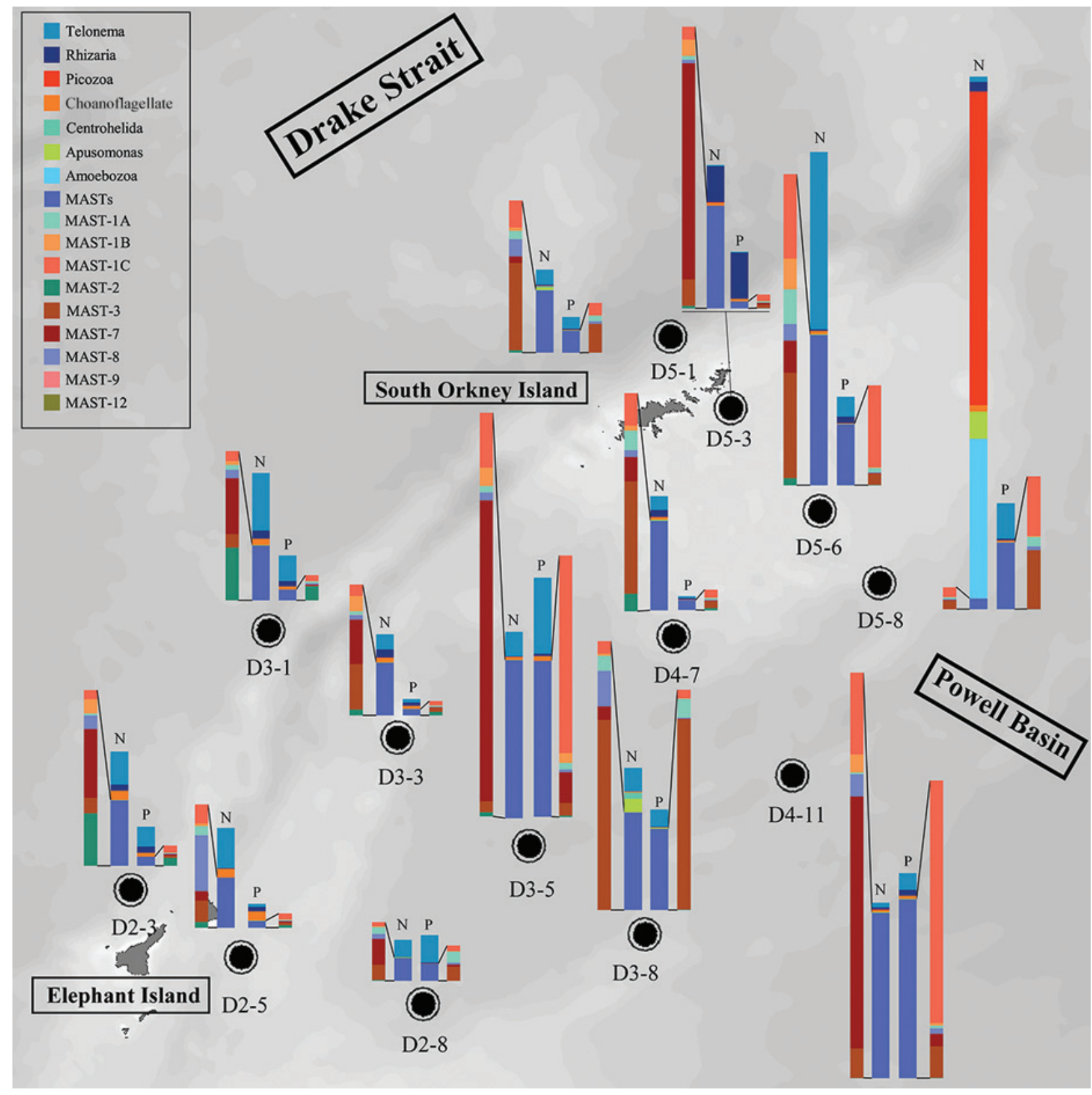

Fig. 3 Heterotrophic flagellate community structure at different stations, based on the reads data sets. Stacked column graphs illustrate the abundances of the dominant taxa of heterotrophic flagellates in this study. The middle two columns in each set represent the community structure of HNF and HPF; P presents HPF and N represents HNF. The columns on two sides are the distribution of each clade of MAST.

correlation with environmental factors. For instance, although MASTs were the dominant taxon, only the MAST-2 clade showed significant correlations with environmental factors. MAST-2 correlated negatively with temperature, salinity and chl $a$ and positively with bacteria density.

Conversely, the MAST-12 clade correlated negatively with bacteria density. Choanoflagellates, Telonemia and MAST-2 correlated negatively with temperature. Amongst them, Telonemia showed a lower negative correlation. In conclusion, only two taxa showed a significant correlation with only a single parameter measured in this study, whereas three taxa were correlated significantly with more than one environmental factor. The remaining taxa showed no correlation with any environmental factor.

Spearman's correlation analyses showed that the correlations amongst the dominant taxa of HFs were also 

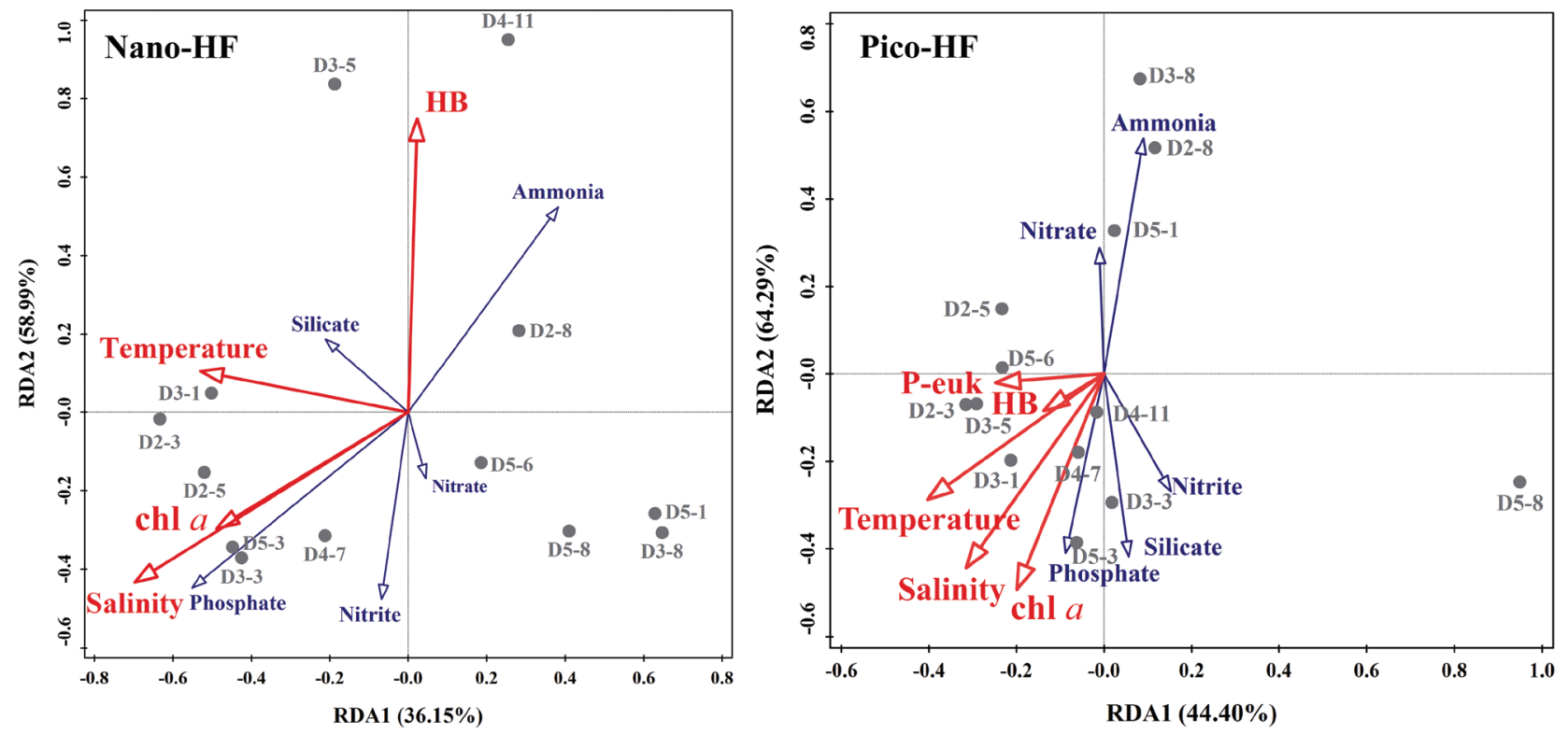

Fig. 4 Redundancy analysis of the environmental factors affecting HPF and HNF communities, based on the OTU data sets. Red arrows represent environmental factors, blue arrows represent nutritional factors and each dot represents a sample. The labels on the graph show the percentage differences between the HPF group and the HNF group.

significant, indicating that biological interactions are also an essential factor influencing HF diversity and community structure in the sea around the northern tip of the Antarctic Peninsula. From the correlation matrix (Fig. 5), nine of the 16 dominant taxa in the HPF group were correlated significantly with the presence of at least two other taxa, and eight of the 14 dominant taxa in the HNF group were correlated significantly with the presence of at least two other genera. Of the correlations between taxa amongst the HNF group populations, Rhizaria, choanoflagellates, Centrohelida, MAST-1A, MAST-1C, MAST-2 and MAST-3 were correlated significantly with more than two other phyla or genera. Most of these phyla or genera were correlated strongly with each other, either positively or negatively. Amoebozoa, Apusomonas, MAST-1B, MAST-7 and MAST-8 only showed significant correlations with one other taxon. There were no significant correlations between Telonemia or MAST-12 and any other taxon.

\section{Discussion}

\section{Taxonomic compositions with HPFs and HPFs distribution}

According to the results above, the community structure in most of the stations was similar, and the abundance and diversity of HNF group were lower than the HPF group. Amongst the two groups with different size, MAST and Telonemia were dominant at most stations. However, the community structure at some stations was significantly different from that at other stations. Luo et al. (2016), who investigated the diversity of microbial eukaryotes in the coastal region of the Fildes Peninsula, Antarctic, also showed that MASTs and Telonemia occupied significant positions in the HF group, whereas Picozoa accounted for less than $2.43 \%$ of reads per sampling site. In this research, Picozoa, Amoebozoa and Centrohelida were present in only some samples; the remaining five taxa were detected in all samples. Picozoa was thought to prefer colloidal material or small viruses more than specific bacteria and phytoplankton prey, which may limit the scope of survival (Seenivasan et al. 2013; Thaler \& Lovejoy 2015).

There were more sequences reads from D5-6 and D5-8 than from the other stations, indicating that the abundance of HFs near the Weddell Sea was much higher than the other areas in the Powell Basin. The community structure at D5-8 was significantly different from those at the other stations. At D5-8, the number of reads for and the relative percentage of Rhizaria was higher than at all other stations. Amoebozoa and Picozoa were mainly found at D5-8 and were very rare at the other stations. However, the environmental factors at D5-3 and D5-8 did not differ significantly from those at the other stations, so the differences between their community structure were possibly related to water mass interactions, biological interactions or other factors.

The numbers of OTUs and reads were much lower in the HNF group than in the HPF group, which may be evidence of microbial miniaturization in the polar regions 


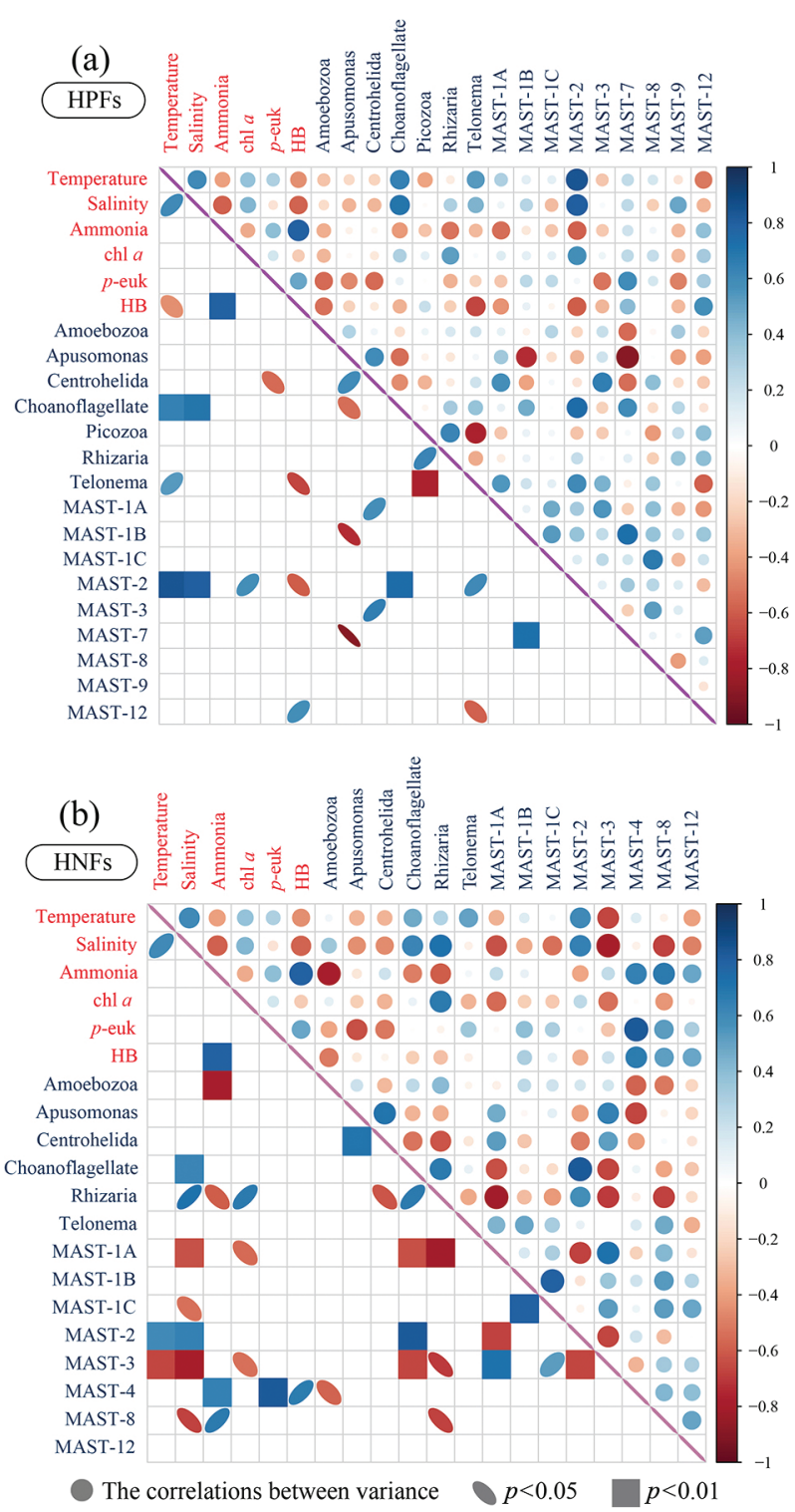

Fig. 5 Pairwise comparisons of environmental factors and heterotrophic flagellate taxa; the colour, size and gradient of symbols denote Spearman's correlation coefficients.

(Hanson et al. 2012). In the D2 section, the proportion of Telonemia was higher than that of MASTs, implying that the abundance of nano-sized Telonemia in this section was higher than that of nano-MASTs. Because the number of reads in the samples from the stations in this section was relatively small, it cannot be inferred that Telonemia had a survival advantage over MASTs in this area.

\section{Distribution of MASTs}

As the dominant group in the HF community, MASTs exhibit high taxonomic diversity, and members of this taxon play many ecological roles in the marine ecosystem (Massana et al. 2006). The MAST-1, MAST-2, MAST-3 and MAST-7 clades are common in the Arctic Ocean (Lovejoy et al. 2006). MAST-1, which includes three groups, was particularly abundant in the Antarctic Peninsula samples (Massana et al. 2006). MAST-3 is the most abundant MAST clade worldwide (Logares et al. 2012). MAST-7 is also widespread globally and is predominantly reported in Arctic waters (Massana et al. 2006). Luo et al. (2016) reported that off the coast of King George Island in the Antarctic, MAST-1A was the most abundant member of MAST-1, and MAST-1C was the second major group. In contrast, MAST-1B was rarely detected in any sample. These findings are consistent with our results, suggesting a widespread, relatively stable distribution of MAST-1 off the Antarctic Peninsula coast. However, in Luo's research, MAST-8 was more abundant than MAST-7, and MAST-3 was rarely detected, which is inconsistent with our results. These data suggest that regional differences significantly affect MAST clades other than MAST-1.

In recent studies, several differences in the spatial scale distribution of the MAST clades have been reported, which may be attributable to different food sources and predation pressures (Piwosz \& Pernthaler 2010; Lin et al. 2012). Comeau et al. (2013) noted that MASTs tend to coexist with diatoms. In some grazing experiments and stable isotope probing experiments, MAST- 1 and MAST-7 consumed heterotrophic bacteria and cyanobacteria (Frias-Lopez et al. 2009; Massana et al. 2009). Cyanobacteria are less prevalent in the Arctic and Antarctic than in other parts of the world (Waleron et al. 2007; Grebert et al. 2018), so it has been suggested that MAST-1 and MAST-7 may feed on the abundant, similarly sized photosynthetic eukaryote Micromonas in polar areas (Lovejoy et al. 2007). In the present study, MAST-7 in the HNF group correlated significantly with the abundance of photosynthetic eukaryotes and heterotrophic bacteria, explaining the different distribution of MASTs from that in the nearby sea.

\section{Effects of environmental and biological interactions}

There were no significant differences amongst the environmental factors in this study, such as temperature, nutrient salt, sampling depth and chl a concentration, at the various sites. Of these environmental factors, salinity and bacteria's biomass more significantly affected HF diversity and community structure than the other environmental factors. According to previous studies, the bacterial community structure also influences the diversity and community structure of HFs. Grazing 
experiments have shown that many dominant genera of HFs have different predation tendencies. For instance, Picozoa is thought to consume colloidal material and, perhaps, small viruses and may be less constrained by prey availability (Seenivasan et al. 2013). Telonemia is thought to feed on cryptophytes and other nanophytoplankton (Brate et al. 2010), so members of that phylum may be more abundant in oligotrophic systems dominated by phytoflagellates (Ardyna et al. 2011). The majority of taxa in the Rhizaria are described as predators of bacteria and small phytoplankton and have been observed in association with diatoms (Thaler \& Lovejoy 2012). According to the research of Cao et al. (2019) and Chen et al. (2021), the bacteria community structure in station D5-8 was different from other stations. In D5-8, the dominant taxon and the proportion of the total bacterial population attributable to the dominant genus also differed from other stations. The bacterial diversity was significantly higher than at the other stations (Cao et al. 2019). Therefore, the bacterial community structure may be an important factor affecting the HF community structure at D5-8. According to the Spearman's correlation analyses, the result indicates that both cooperation and competition are operating amongst these taxa and the possibility of mutual predation. The specific predation relationship needs to be further studied through predation experiments.

\section{Geographic distributiozn}

HFs occur throughout the world, and the dominant groups vary in different habitats. The flagellate clades of Rhizaria that belong to Cryomonadida, like Cryothecomonas and Protaspis (Mylnikova \& Mylnikov 2012), have been reported in sea ice and the water column (Garrison et al. 2005), dominating in sea ice (Comeau et al. 2013) and found at lower abundances in the water column (Thaler $\delta$ Lovejoy 2015). In the present research, the samples were collected from seawater, and Rhizaria had fewer sequences than MAST and Telonemia in both HNF and HPF groups. Some other flagellate clades that belong to Cryomonadida, like Rhogostoma, Rhizapis and Capsellina (Mylnikova \& Mylnikov 2012), have been reported only in freshwater. Telonemia has been detected with 18S rRNA analyses from freshwater and seawater, including marine-specific clades (Brate et al. 2010). The marine-specific clades of Telonemia may influence the proportion of Telonemia in the HF community structure. Choanoflagellates occur in freshwater, marine water, sea ice (Ikavalko \& Gradinger 1997) and even sediments (Dayel et al. 2011). Choanoflagellates were reported to be more dominant and phylogenetically more diverse than most clades of HFs in the Canada Basin and had a few phylotypes that were restricted to a given region, like sea ice (Thaler \& Lovejoy 2015). Compared with MAST, Telonemia and Rhizaria, choanoflagellates occupy a lower proportion in the community but have a higher proportion at some stations. As for other reported MAST clades, MAST-2 is reported as the most abundant MAST in sea ice (Piwosz et al. 2013), but in the present research, MAST-2 was not dominant in seawater. MAST-4 was not detected in this area; it has been reported widespread in global oceans but appears to be absent from cold waters, including the Arctic (Rodriguez-Martinez et al. 2013).

In the coastal area of the Antarctic Peninsula's northern tip, fluctuations in the seabed topography interact with ocean currents, producing a very complex water exchange process (Hernandez-Molina et al. 2006) that may affect the biodiversity of the coastal Antarctic ecosystem. The area investigated in the present study has a unique geographic location in terms of the Southern Ocean currents (Jiuxin et al. 2016). As the area is the nexus between the Antarctic Circumpolar Current and the Weddell Sea Circulation, seawater is exchanged there, which may cause planktonic communities to mix. Existing data and related studies of water-mass interactions show that the surface water in the Powell Basin, off the northern Antarctic Peninsula, was homogeneous during the sampling period of the present study (Jiuxin et al. 2016; Cao et al. 2019; Chen et al. 2021). The WDW and the higher-temperature water masses observed in the D2 section are unlikely to be locally formed and transported along the continental slope. This may be one reason why the proportion of Telonemia was higher than that of MASTs in the D2 section. The highest temperature in the D5 section occurred to the south of D5-8, which is the core of the WDW. The area around D5-8 may be the part of the WDW in the Weddell Sea that flows out from the South Orkney platform (Jiuxin et al. 2016). This outflow may contribute to the abnormal community structure at D5-8. The sequence reads at D5-6 and D5-8 were much higher than at the other stations, indicating that the abundance of HFs was much higher near the Weddell Sea than at the other stations in the Powell Basin. Recent studies have shown that many marine microbiota in the Antarctic have circumpolar distributions, indicating that the Antarctic Circumpolar Current and the Antarctic Coastal Current have a wide range of influence in this region. Therefore, the HF community structure in this region may be similar to other regions around the South Pole, which needs further study.

\section{Conclusion}

In summary, the results of this study suggest that salinity, bacterial biomass and the biological interactions 
between dominant taxa contribute more to HF diversity and community structure than other environmental factors. HFs of different sizes display different levels of diversity and different community structure. However, within the same particle-size class, each station's dominant taxa were similar. The shared OTUs in these samples confirmed the similarity of the distributions of the most significant taxa. The HF community structure at D5-8 differed significantly from that at the other stations, and the bacterial community structure at D5-8 was also different from other stations at the same time. To some extent, this result also indicates that the bacteria community plays a significant role in influencing the diversity and community structure of HFs in the same habitat, and more data and research are needed on the influence of other food sources on flagellate.

In this study, we report the occurrence and abundance of HNFs and HPFs, which are considered to play essential roles in the Antarctic ecosystem. At present, little information is available on the distributions and structure of coastal microbial communities around the Antarctic Peninsula, especially heterotrophic protozoa. The monitoring data on HF community structure reported in this study exemplify samples that were collected in summer in this region and may be compared with future data to investigate the sensitivity of HFs to potential climate change.

\section{Acknowledgements}

The authors are grateful to Professor Shi Jiuxin of the Ocean University of China for kindly providing temperature and salinity data and to Professor Pan Jianming of the Second Institute of Oceanography for providing nutrient data. The cruise was supported by the RV Xuelong ice-breaker.

\section{Disclosure statement}

The authors report no potential conflict of interest.

\section{Funding}

This study was funded by the Chinese Polar Environment Comprehensive Investigation \& Assessment Programs (CHINARE-2011-2015), an international cooperation programme of the Chinese National Arctic and Antarctic Research Expedition (IC201514), and the National Natural Science Foundation of China (grant nos. 41206189, 41476168, 41976230 and 41906201).

\section{Data availability statement}

The data sets generated for this study can be found in the National Center for Biotechnology Information Sequence Read Archive under BioProject number PRJNA642996, accessible online at https://dataview.ncbi.nlm.nih.gov/ object / PRJNA 642996? reviewer $=\operatorname{tg} 7$ j mm $2 \mathrm{k} 1$ o 9 qge4qv7f8bqurdd.

\section{References}

Ardyna M., Gosselin M., Michel C., Poulin M. \& Tremblay J.E. 2011. Environmental forcing of phytoplankton community structure and function in the Canadian High Arctic: contrasting oligotrophic and eutrophic regions. Marine Ecology Progress Series 442, 37-57, doi: 10.3354/ meps09378.

Arndt H., Dietrich D., Auer B., Cleven E.-J., Grafenhan T., Weitere M. \& Mylnikov A.P. 2000. Functional diversity of heterotrophic flagellates in aquatic ecosystems. In B.S.C. Leadbeater \& J.C. Green (eds.): The flagellates: unity, diversity and evolution. Pp. 240-268. London: Taylor \& Francis.

Bonkowski M. 2004. Protozoa and plant growth: the microbial loop in soil revisited. New Phytologist 162, 617-631, doi: 10.1111/j.1469-8137.2004.01066.x.

Bråte J., Klaveness D., Rygh T., Jakobsen K.S. \& ShalchianTabrizi K. 2010. Telonemia-specific environmental 18S rDNA PCR reveals unknown diversity and multiple marine-freshwater colonizations. BMC Microbiology 10, article no. 168, doi: 10.1186/1471-2180-10-168.

Cao S.N., He J.F., Zhang F., Lin L., Gao Y. \& Zhou Q.M. 2019. Diversity and community structure of bacterioplankton in surface waters off the northern tip of the Antarctic Peninsula. Polar Research 38, article no. 3491, doi: 10.33265/polar.v38.3491.

Cermeno P. \& Falkowski P.G. 2009. Controls on diatom biogeography in the ocean. Science 325, 1539-1541, doi: 10.1126/science.1174159.

Chen Z.Y., Lu Z.B., Gao Y., Hao Q. \& He J.F. 2021. Determination of bacterioplankton abundance, production and carbon budget in the northwest Weddell Sea. Geomicrobiology Journal 38, 607-619, doi: 10.1080/ 01490451.2021 .1914783$.

Comeau A.M., Philippe B., Thaler M., Gosselin M., Poulin M. \& Lovejoy C. 2013. Protists in Arctic drift and landfast sea ice. Journal of Phycology 49, 229-240, doi: 10.1111/ jpy. 12026.

Dayel M.J., Alegado R.A., Fairclough S.R., Levin T.C., Nichols S.A., McDonald K. \& King N. 2011. Cell differentiation and morphogenesis in the colony-forming choanoflagellate Salpingoeca rosetta. Developmental Biology 357, 73-82, doi: 10.1016/j.ydbio.2011.06.003.

Domaizon I., Viboud S. \& Fontvieille D. 2003. Taxonspecific and seasonal variations in flagellates grazing on heterotrophic bacteria in the oligotrophic Lake Annecyimportance of mixotrophy. FEMS Microbiology Ecology 46, 317-329, doi: 10.1016/S0168-6496(03)00248-4. 
Falk-Petersen S., Pavlov V., Timofeev S. \& Sargent J.R. 2007. Climate variability and possible effects on Arctic food chains: the role of Calanus. In J.B. Ørbæk et al. (eds.): Arctic alpine ecosystems and people in a changing environment. Pp. 147-166. Berlin: Springer.

Fenchel T. \& Finlay B.J. 2004. The ubiquity of small species: patterns of local and global diversity. Bioscience 54, 777-784, doi: 10.1641/0006-3568(2004)054[0777:Tuossp]2.0.Co;2.

Filker S., Stock A., Breiner H.W., Edgcomb V., Orsi W., Yakimov M.M. \& Stoeck T. 2013. Environmental selection of protistan plankton communities in hypersaline anoxic deep-sea basins, eastern Mediterranean Sea. Microbiologyopen 2, 54-63, doi: 10.1002/mbo3.56.

Fortier L., Sirois P., Michaud J. \& Barber D. 2006. Survival of Arctic cod larvae (Boreogadus saida) in relation to sea ice and temperature in the Northeast Water Polynya (Greenland Sea). Canadian Journal of Fisheries and Aquatic Sciences 63, 1608-1616, doi: 10.1139/F06-064.

Frias-Lopez J., Thompson A., Waldbauer J. \& Chisholm S.W. 2009. Use of stable isotope-labelled cells to identify active grazers of picocyanobacteria in ocean surface waters. Environmental Microbiology 11, 512-525, doi: 10.1111/j.1462-2920.2008.01793.x.

Garrison D.L., Gibson A., Coale S.L., Gowing M.M., Okolodkov Y.B., Fritsen C.H. \& Jeffries M.O. 2005. Seaice microbial communities in the Ross Sea: Autumn and summer biota. Marine Ecology Progress Series 300, 39-52, doi: $10.3354 /$ meps300039.

Grebert T., Dore H., Partensky F., Farrant G.K., Boss E.S., Picheral M., Guidi L., Pesant S., Scanlan D.J., Wincker P., Acinas S.G., Kehoe D.M. \& Garczarek L. 2018. Light color acclimation is a key process in the global ocean distribution of Synechococcus cyanobacteria. Proceedings of the National Academy of Sciences of the United States of America 115, E2010-E2019, doi: 10.1073/pnas.1717069115.

Hamilton A.K., Lovejoy C., Galand P.E. \& Ingram R.G. 2008. Water masses and biogeography of picoeukaryote assemblages in a cold hydrographically complex system. Limnology and Oceanography 53, 922-935, doi: 10.4319/ lo.2008.53.3.0922.

Hanson C.A., Fuhrman J.A., Horner-Devine M.C. \& Martiny J.B. 2012. Beyond biogeographic patterns: processes shaping the microbial landscape. Nature Reviews Microbiology 10, 497-506, doi: 10.1038/nrmicro2795.

He J.F., Zhang F., Lin L., Cai M.H., Yang H.Z. \& Wang X.G. 2012. Effects of the 2010 Chile and 2011 Japan tsunamis on the Antarctic coastal waters as detected via online mooring system. Antarctic Science 24, 665-671, doi: 10.1017/S0954102012000326.

Hernandez-Molina F.J., Larter R.D., Rebesco M. \& Maldonado A. 2006. Miocene reversal of bottom water flow along the Pacific Margin of the Antarctic Peninsula: stratigraphic evidence from a contourite sedimentary tail. Marine Geology 228, 93-116, doi: 10.1016/j.margeo.2005.12.010.

Ikavalko J. \& Gradinger R. 1997. Flagellates and heliozoans in the Greenland Sea ice studied alive using light microscopy. Polar Biology 17, 473-481, doi: 10.1007/s003000050145.

Jiuxin S., Yongming S., Yutian J., Guanghua H. \& Miao W. 2016. Water masses and exchanges in the region around the northern tip of the Antarctic Peninsula observed in summer 2011/2012. Chinese Journal of Polar Research 28, 67-79.

Jones S.E. \& Lennon J.T. 2010. Dormancy contributes to the maintenance of microbial diversity. Proceedings of the National Academy of Sciences of the United States of America 107, 5881-5886, doi: 10.1073/pnas.0912765107.

Laidre K.L., Stirling I., Lowry L.F., Wiig O., Heide-Jorgensen M.P. \& Ferguson S.H. 2008. Quantifying the sensitivity of Arctic marine mammals to climate-induced habitat change. Ecological Applications 18, S97-S125, doi: 10.1890/06-0546.1.

Li W.K.W., McLaughlin F.A., Lovejoy C. \& Carmack E.C. 2009. Smallest algae thrive as the Arctic Ocean freshens. Science 326, 539-539, doi: 10.1126/science.1179798.

Lin Y.C., Campbell T., Chung C.C., Gong G.C., Chiang K.P. \& Worden A.Z. 2012. Distribution patterns and phylogeny of marine stramenopiles in the north Pacific Ocean. Applied and Environmental Microbiology 78, 3387-3399, doi: 10.1128/AEM.06952-11.

Logares R., Audic S., Santini S., Pernice M.C., de Vargas C. \& Massana R. 2012. Diversity patterns and activity of uncultured marine heterotrophic flagellates unveiled with pyrosequencing. ISME Journal 6, 1823-1833, doi:10.1038/ ismej.2012.36.

Lovejoy C., Massana R. \& Pedros-Alio C. 2006. Diversity and distribution of marine microbial eukaryotes in the Arctic Ocean and adjacent seas. Applied Environmental Microbiology 72, 3085-3095, doi: 10.1128/ AEM.72.5.3085-3095.2006.

Lovejoy C., Vincent W.F., Bonilla S., Roy S., Martineau M.J., Terrado R., Potvin M., Massana R. \& Pedros-Alio C. 2007. Distribution, phylogeny, and growth of cold-adapted picoprasinophytes in Arctic seas. Journal of Phycology 43, 78-89, doi: 10.1111/j.1529-8817.2006.00310.x.

Luo W., Li H.R., Gao S.Q., Yu Y., Lin L. \& Zeng Y.X. 2016. Molecular diversity of microbial eukaryotes in sea water from Fildes Peninsula, King George Island, Antarctica. Polar Biology 39, 605-616, doi: 10.1007/s00300-015-1815-8.

Massana R. 2011 . Eukaryotic picoplankton in surface oceans. Annual Review of Microbiology 65, 91-110, doi: 10.1146/ annurev-micro-090110-102903.

Massana R., Castresana J., Balague V., Guillou L., Romari K., Groisillier A., Valentin K. \& Pedros-Alio C. 2004. Phylogenetic and ecological analysis of novel marine stramenopiles. Applied Environmental Microbiology 70, 3528-3534, doi: 10.1128/AEM.70.6.3528-3534.2004.

Massana R., Terrado R., Forn I., Lovejoy C. \& PedrosAlio C. 2006. Distribution and abundance of uncultured heterotrophic flagellates in the world oceans. Environmental Microbiology 8, 1515-1522, doi: $10.1111 / \mathrm{j}$. 1462-2920.2006.01042.x.

Massana R., Unrein F., Rodriguez-Martinez R., Forn I., Lefort T., Pinhassi J. \& Not F. 2009. Grazing rates and functional diversity of uncultured heterotrophic flagellates. ISME Journal 3, 588-596, doi: 10.1038/ismej.2008.130.

McKenna S., Meyer M., Gregg C. \& Gerber S. 2016. s-CorrPlot: an interactive scatterplot for exploring correlation. Journal of Computational and Graphical Statistics 25, 445-463, doi: 10.1080/10618600.2015.1021926. 
Monier A., Sudek S., Fast N.M. \& Worden A.Z. 2013. Gene invasion in distant eukaryotic lineages: discovery of mutually exclusive genetic elements reveals marine biodiversity. ISME Journal 7, 1764-1774, doi: 10.1038/ismej.2013.70.

Müller T.J. 2007. Determination of salinity. In K. Grasshoff et al. (eds.): Methods of seawater analysis. 3rd edn. Pp. 41-74. Weinheim: Wiley-VCH.

Mylnikova Z.M. \& Mylnikov A.P. 2012. Structure of filose amoeba Rhogostoma minus Belar 1921 (Cryomonadida, Cercozoa) cell. Inland Water Biology 5, 236-240, doi: 10.1134/S1995082912020101.

Orsi W., Edgcomb V., Jeon S., Leslin C., Bunge J., Taylor G.T., Varela R. \& Epstein S. 201 1. Protistan microbial observatory in the Cariaco Basin, Caribbean. II. Habitat specialization. ISME Journal 5, 1357-1373, doi: 10.1038/ismej.2011.7.

Piwosz K. \& Pernthaler J. 2010. Seasonal population dynamics and trophic role of planktonic nanoflagellates in coastal surface waters of the southern Baltic Sea. Environmental Microbiology 12, 364-377, doi: 10.1111/j. 1462-2920.2009.02074.x.

Piwosz K., Wiktor J.M., Niemi A., Tatarek A. \& Michel C. 2013. Mesoscale distribution and functional diversity of picoeukaryotes in the first-year sea ice of the Canadian Arctic. ISME Journal 7, 1461-1471, doi:10.1038/ ismej.2013.39.

Pruesse E., Quast C., Knittel K., Fuchs B.M., Ludwig W., Peplies J. \& Glockner F.O. 2007. SILVA: a comprehensive online resource for quality checked and aligned ribosomal RNA sequence data compatible with ARB. Nucleic Acids Research 35, 7188-7196, doi: 10.1093/nar/gkm864.

Rodriguez-Martinez R., Rocap G., Salazar G. \& Massana R. 2013. Biogeography of the uncultured marine picoeukaryote MAST-4: temperature-driven distribution patterns. ISME Journal 7, 1531-1543, doi: 10.1038/ismej.2013.53.

Schlitzer R., Anderson R.F., Dodas E.M., Lohan M., Geibere W., Tagliabue A., Bowie A., Jeandel C., Maldonado M.T., Landing W.M., Cockwell D., Abadie C., Abouchami W., Achterberg E.P., Agather A., Aguliar-Islas A., van Aken H.M., Andersen M., Archer C., Auro M., de Baar H.J., Baars O., Baker A.R., Bakker K., Basak C., Baskaran M., Bates N.R., Bauch D., van Beek P., et al. 2018. The GEOTRACES Intermediate Data Product 2017. Chemical Geology 493, 210-223, doi: 10.1016/j.chemgeo.2018.05.040.
Schloss P.D., Westcott S.L., Ryabin T., Hall J.R., Hartmann M., Hollister E.B., Lesniewski R.A., Oakley B.B., Parks D.H., Robinson C.J., Sahl J.W., Stres B., Thallinger G.G., Van Horn D.J. \& Weber C.F. 2009. Introducing Mothur: open-source, platform-independent, community-supported software for describing and comparing microbial communities. Applied Environmental Microbiology 75, 7537-7541, doi: 10.1128/AEM.01541-09.

Seenivasan R., Sausen N., Medlin L.K. \& Melkonian M. 2013. Picomonas judraskeda gen. et sp nov.: the first identified member of the Picozoa phylum nov., a widespread group of picoeukaryotes, formerly known as "picobiliphytes." PLoS One 8, article no. e59565, doi: 10.1371/journal.pone.0059565.

Sherr E.B. \& Sherr B.F. 2002. Significance of predation by protists in aquatic microbial food webs. Antonie Van Leeuwenhoek 81, 293-308, doi: 10.1023/a:1020591307260.

Sohrin R., Imazawa M., Fukuda H. \& Suzuki Y. 2010. Fulldepth profiles of prokaryotes, heterotrophic nanoflagellates, and ciliates along a transect from the equatorial to the Subarctic central Pacific Ocean. Deep-Sea Research Part II 57, 15371-15350, doi: 10.1016/j.dsr2.2010.02.020.

Thaler M. \& Lovejoy C. 2012. Distribution and diversity of a protist predator Cryothecomonas (Cercozoa) in Arctic marine waters. Journal of Eukaryotic Microbiology 59, 291-299, doi: 10.1111/j.1550-7408.2012.00631.x.

Thaler M. \& Lovejoy C. 2015. Biogeography of heterotrophic flagellate populations indicates the presence of generalist and specialist taxa in the Arctic Ocean. Applied Environmental Microbiology 81, 2137-2148, doi: 10.1128/ AEM.02737-14.

Waleron M., Waleron K., Vincent W.F. \& Wilmotte A. 2007. Allochthonous inputs of riverine picocyanobacteria to coastal watersin the Arctic Ocean. FEMS Microbiology Ecology 59, 356-365, doi: 10.1111/j.1574-6941.2006.00236.x.

Zhang F., Cao S.A., Gao Y. \& He J.F. 2019. Distribution and environmental correlations of picoeukaryotes in an Arctic fjord (Kongsfjorden, Svalbard) during the summer. Polar Research 38, article no. 3390, doi: 10.33265/polar. v38.3390.

Zhang F., He J.F., Lin L. \& Jin H.Y. 2015. Dominance of picophytoplankton in the newly open surface water of the central Arctic Ocean. Polar Biology 38, 1081-1089, doi: 10.1007/s00300-015-1662-7. 